\title{
Comparative Study of Electrophrenic Nerve Stimulation and Mechanical Ventilatory Support in Traumatic Spinal Cord Injury
}

\author{
R. E. Carter, M.D., ${ }^{1,2}$ W. H. Donovan, M.D., ${ }^{1,2}$ L. Halstead, M.D., ${ }^{1,2}$ \\ M. A. Wilkerson, B.S. ${ }^{1}$ \\ ${ }^{1}$ Texas Regional Spinal Cord Injury Center, The Institute for Rehabilitation and \\ Research, 1333 Moursund Avenue, Houston, TX 77030. ${ }^{2}$ Department of Reha- \\ bilitation, Baylor College of Medicine, 1200 Moursund Avenue, Houston, TX \\ 77030, U.S.A.
}

\section{Summary}

Over the past two decades, the number of surviving apneic spinal cord injured patients has been increasing. Mechanical ventilation for home maintenance has been supplemented by electrophrenic respiration (EPR) since 1970. Nineteen patients who were totally mechanical ventilator dependent at discharge from rehabilitation in a spinal cord centre are compared with 18 patients discharged on EPR. There were more young males in the EPR group while the overall average ages were approximately the same. The mortality rates were approximately equal although the mechanical ventilator dependent patients expired earlier than the EPR group. Survivors on mechanical ventilation lived longer on an average and the vast majority of both groups were discharged to their home. There needs to be the establishment of a ventilatory dependent registry for spinal cord injury.

Key words: Tetraplegia; Apnea; Mechanical ventilation; Electrophrenic respiration; Longevity.

\section{Introduction}

Since the organisation of The Institute for Rehabilitation and Research (TIRR) Spinal Cord Injury Center in 1960, over 2600 new spinal cord injury patients have been admitted. More than $4.2 \%$ (approximately 110 ) of these patients were admitted with a neurological level of C3 or above and were essentially apneic on admission. In the past several years, this number has apparently been escalating due, in part, to more of the general public having knowledge of CPR, outlying hospitals being equipped with improved respiratory equipment, proliferation of trained emergency medical technicians, and improvement of skills and equipment in respiratory therapy. As a result of these multiple factors more

Correspondence to: R. E. Carter, M.D., Vice-President, Medical Affairs Texas Regional Spinal Cord Injury Center, The Institute for Rehabilitation and Research, 1333, Moursund Avenue, Houston, Texas 77030, U.S.A. 
apneic spinal cord injury patients are surviving the scene of the injury and the acute trauma centres and are later being referred to rehabilitation facilities.

One portion of apneic patients admitted with new spinal cord injuries to rehabilitation centres are those with incomplete injuries who subsequently recover enough respiratory function to ultimately be weaned from all forms of ventilatory support. A second portion of the group of apneic new spinal cord injured patients is that of the mid-cervical injuries who have ascending lesions resulting in loss of function in one or both diaphragms for a period of months only to subsequently recover this function as the neurologic level descends to the site of permanent damage. A third portion of the group of apneic new spinal cord injured patients remain on full-time ventilatory support upon discharge from the spinal cord injury centre. Over the past 17 years, TIRR has discharged 37 ventilatory dependent spinal cord injury patients. Of these, 19 were on mechanical ventilators and 18 were on electrophrenic respirators (EPR) (Glenn et al., 1973).

\section{Patients and methods}

This particular study covers the period from 1968 through December, 1985. A review of the records of all spinal cord injured patients was performed on these who were totally dependent ( 24 hours per day) on ventilatory support at their first discharge from TIRR. Demographic information was obtained through review of their medical records and all patients were either seen in clinic or contacted by telephone in December, 1985 for long-term follow-up information.

The ventilator dependent group numbered a total of 19 patients which consisted of 17 males and two females while the EPR group consisted of a total of 18 patients in which there were nine males and nine females. The average age at onset of injury (Table I) in the ventilatory dependent group was 20 years for the males and 24 years for the females with an overall average of 20 years (range 14 to 29 years). In the EPR group the average age at onset was 14 years in the males and 24 years in the females with an overall average of 19 years (range four to 54 years).

Mortality studies indicated that out of the 19 ventilatory dependent patients, six $\left(32^{\circ}{ }_{0}\right)$ had expired while in the 18 EPR patients, seven $\left(39^{\circ}\right)$ had expired

Table I TIRR Study of Ventilation Dependent Persons with SCI: Average Age at Onset of SCI

\begin{tabular}{lcc}
\hline & $\begin{array}{c}\text { Mechanical ventilation dependent } \\
\text { mean (range) }\end{array}$ & $\begin{array}{c}\text { EPR } \\
\text { mean (range) }\end{array}$ \\
\hline Males & 20 yrs $(14-29)$ & 14 yrs $(4-23)$ \\
Females & 24 yrs $(20-28)$ & 24 yrs $(7-54)$ \\
Total & 20 yrs $(14-29)$ & 19 yrs $(4-54)$ \\
\hline
\end{tabular}

\begin{tabular}{lcc}
\hline Table II & TIRR Study of Ventilation Dependent Persons with SCI: Population at December, 1985 \\
\hline & Mechanical ventilation dependent & EPR \\
& number $\left({ }^{\circ}\right)$ & number $(\%)$ \\
\hline Living & $13\left(68^{\circ}{ }_{0}{ }_{0}\right)$ & $11\left(61^{\circ}{ }_{0}\right)$ \\
Expired & $6\left(32^{\circ}{ }_{0}\right)$ & $\left.739^{\circ}\right)$ \\
Total & $19\left(100^{\circ}{ }_{0}\right)$ & $18\left(100^{\circ}{ }_{0}\right)$ \\
\hline
\end{tabular}


(Table II). The causes of death in the mechanical ventilator dependent group were: three cardiac deaths; one renal; one gastrointestinal bleed; and one unknown. The causes of death in the EPR group were: two cardiac deaths; one pulmonary infection; one pulmonary embolus; and three unknown. It is of interest to note that several of the cardiac deaths and possibly the unknown deaths as well were due to sudden death with no known antecedent symptomatology or illness. Most of these were felt to be due to cardiac arrest, probably on a vagal basis. Several died in their sleep at home and two were found dead sitting in their wheelchairs while unattended. The average time in months from onset of injury to death in the mechanical ventilator group (six patients) was 13 months (Table III). In the EPR group (seven patients), the average time from onset of injury to EPR surgery was 17 months and the average time from EPR surgery to death was 31 months giving a total time from onset of injury to death of 48 months. Thus it appears that the time from onset of injury to death in the EPR group was between three and four times the duration of those that were mechanical ventilator dependent.

In the group of 13 living mechanical ventilator dependent patients, the average time from onset of injury through December, 1985 was 76 months (Table IV).

Table III TIRR Study of Ventilation Dependent Persons with SCI: Average Duration in Months from Onset of SCI to Death

\begin{tabular}{lcc}
\hline & $\begin{array}{c}\text { Mechanical ventilation dependent } \\
(\mathbf{N}=6 \text { patients }) \text { months }\end{array}$ & $\begin{array}{c}\text { EPR } \\
(\mathrm{N}=7 \text { patients }) \text { months }\end{array}$ \\
\hline Onset to E.P.R. surgery & & 17 \\
E.P.R. surgery to death & 13 & 31 \\
Onset to death & 13 & 48 \\
\hline
\end{tabular}

Table IV TIRR Study of Ventilation Dependent Persons with SCI: Average Duration in Months of Survivors from SCI Onset to December, 1985

\begin{tabular}{lcc}
\hline & $\begin{array}{c}\text { Mechanical ventilation dependent } \\
(\mathrm{N}=13 \text { patients }) \text { months }\end{array}$ & $\begin{array}{c}\text { EPR } \\
(\mathrm{N}=11 \text { patients }) \text { months }\end{array}$ \\
\hline Onset to E.P.R. surgery & & 13 \\
E.P.R. surgery to December, 1985 & 76 & 47 \\
SCI onset to December, 1985 & & 60 \\
\hline
\end{tabular}

Longest Survivor: Mechanical ventilation dependent $=14.5 \mathrm{yrs} ; \mathrm{EPR}=17.5 \mathrm{yrs}$.

The longest survivor in this group is now 14.5 years since onset of injury. In the group of 11 surviving patients on electrophrenic stimulators, the average time from onset of injury to EPR surgery was 13 months and from EPR surgery to the present time was 47 months. The average time from onset of injury through December, 1985 was 60 months. The longest surviving EPR patient is currently $17 \cdot 5$ years from onset of injury.

An analysis of the average hours of ventilatory support required per day as of December, 1985 was obtained by a telephone call to the patient and family (Table V). In the mechanical ventilator dependent group, 10 patients required support 24 hours a day while one required 1 hour a day, one required 8 hours a 
Table V TIRR Study of Ventilation Dependent Persons with SCI: Average Hours per Day of Needed Ventilatory Support at December, 1985

\begin{tabular}{cc} 
Mechanic ventilation dependent & EPR \\
\hline 10 at $24 \mathrm{hrs}$ & 7 at $24 \mathrm{hrs}$ \\
1 at $12 \mathrm{hrs} \star$ & 1 at $18 \mathrm{hrs} \star \star$ \\
1 at $8 \mathrm{hrs} \star$ & 1 at $17 \mathrm{hrs} \star \star$ \\
1 at $0 \mathrm{hrs} \star$ & 1 at $13 \mathrm{hrs} \star$ \\
& 1 at $0 \mathrm{hrs} \star \star$
\end{tabular}

${ }^{\star}$ Remaining hrs no ventilatory support. ${ }^{\star \star}$ Remaining hrs on mechanical ventilatory support.

day, and one required no hours of any type of ventilation. The last patient in this group was able to be totally weaned approximately 1 year after the first discharge from their rehabilitation programme. In the 11 surviving EPR patients, seven are being paced 24 hours a day, one 18 hours a day, one 17 hours a day, one 13 hours a day, and one is without EPR. During the remaining hours of the day, these persons are maintained on other types of mechanical ventilatory assistance. The last three patients are those who have had EPRs implanted within the preceding year and, because of pulmonary and other complications, have not yet reached their goal of 24 hours pacing.

The patients were surveyed as to their residence at the time of discharge from their first rehabilitation admission and again 6 months later. In the mechanical ventilator dependent group, 12 patients were discharged to home, four were discharged to a hospital, one unknown, two patients died during the course of their rehabilitation, and no patients were discharged to a nursing home. At 6 months post-discharge follow-up, 10 patients were still at home, one was in a nursing home, one was in a hospital, two were unknown, and three had died within the 6 month period. In the EPR group, 15 patients were discharged to home, none were discharged to a nursing home, two were discharged to another hospital, and one died in the course of his rehabilitation programme. Six months later, 13 patients were still living at home, two had moved to a nursing home, and two had expired within that 6 month period.

\section{Discussion}

While these groups are both small, they appear to be approximately equal in size. The male/female ratio in the mechanical ventilator dependent group approximates that which is usually seen in traumatic spinal cord injury. Interestingly enough, in the EPR group, the males and females were equally split. Age range was essentially the same for males and females in all groups except for the male patients in the EPR group who averaged only 14 years of age. Mortality figures of $32 \%$ and $39 \%$ in the mechanical ventilator dependent group and the EPR group respectively were approximately the same as were the general causes of death in each group.

It is of interest that the long duration from onset of injury to EPR surgery is perhaps a reflection of the economic problems of sponsorship. The first factor is financing a course of rehabilitation, the second is financing the relatively 
expensive electrophrenic stimulator equipment, and the third is to sponsor the time it requires to stabilise the patient from the frequent complications of recurrent pneumonitis and/or atelectasis after sustaining quadriplegia with associated apnea.

Patients on mechanical ventilators appear to have a far shorter time of survival when compared with the electrophrenic stimulator group of patients. Of those surviving, patients in the mechanical ventilator dependent group so far have survived on the average 16 months longer than those in the EPR group. However, the mechanical ventilator dependent group includes several patients who later regained some spontaneous respiration and were able to be fully or partially weaned. Thus, the longevity in this group may be artifically inflated.

All apneic patients are almost uniformly discharged to their home which is partly a result of our hospital policy that requires a pre-admission interview with the patient, family, and sponsors to determine discharge plans before the patient is admitted to the rehabilitation facility. It is an extremely rare finding in our part of the U.S.A. to find a nursing home that is willing to take a patient that is on a ventilator.

Several patients in both groups were discharged back to the original referring hospital or to a hospital in the geographic vicinity of their home, mostly, for a final evaluation prior to moving home so that this hospital would be both knowledgeable and available for further follow-up in case of an acute intercurrent problem.

In the non-survivors, it is apparent that five of the six expired patients in the mechanical ventilator dependent group died during the rehabilitation programme or within the first 6 months following discharge. This is compared to one patient who expired during rehabilitation in the EPR group and two that expired within the first 6 months after discharge.

Around 1970 the adaptability of EPR from patients with sleep apnea to those with apneic quadriplegia afforded us another option in the long-term management of certain numbers of the apneic quadriplegics (Glenn et al., 1985). While experience in success rates in the early days were somewhat variable, the development of suitable criteria for EPR candidates over the last 8 years has given us much better long-term results in reaching total ( 24 hours) maintenance on an EPR system. On a theoretical basis, ventilation utilising the patient's own diaphragmatic musculature by EPR pulls air into the lungs. It is a more physiologic ventilation than respiration with a positive pressure machine which pushes air through a tracheotomy tube into the lungs. Therefore, ventilation by EPR might contribute to patient longevity with less morbidity. Most of the patients that attain 24 hours of pacing with EPR are able to have the tracheotomy plugged and/or removed and replaced with a Plum button.

In summary, continued advances in technology and clinical experience are resulting in an increasing longevity of apneic spinal cord injured patients. A recent multi-centre study (Whiteneck et al., 1985) reports survival percentages of respirator dependent spinal injured patients at $1,3,5,7$, and 9 years postinjury to be $86^{\circ}{ }_{0}, 70^{\circ}{ }_{0}, 63^{\circ}{ }_{0}, 59^{\circ}{ }_{o}$, and $63^{\circ}{ }_{0}$ respectively. The mean total expense for this group was $\$ 305801$ for the average acute and initial rehabilitation management. The subsequent average annual care expense had a mean of $\$ 101246$. Thus, this unique group of surviving patients are providing us with a 
host of medical, moral, economic, psychosocial, community, and vocational problems.

At the present time, no single spinal cord injury facility has a large enough number or experience with apneic spinal cord injured patients to forecast their ultimate outcomes and clinical course. Nor can these traumatic spinal cord injury patients be mixed with those of any other disability groups concerning ventilatory problems and outcomes since their difficulties are so highly unique. Therefore, a collaborative study is being formulated to pool information from multiple facilities in a centralised registry so that we may answer questions concerning mortality and morbidity, home cost, reliability of equipment, equipment cost, place of residence, and primary care givers as well as their ultimate potential for education, vocation, and community productivity.

\section{Acknowledgement}

This work was in part supported by the National Institute of Handicapped Research Grant No. 133 NH50014.

\section{References}

GlenN WWL, Holcomb WG, Hogan J, et al. 1973 Diaphragm pacing by radiofrequency transmission in the treatment of chronic ventilatory insuffiency. The fournal of Thoracic and Cardiovascular Surgery 66(4):505-520.

GLENN WWL, PhelPS ML 1985 Diaphragm pacing by electrical stimulation of the phrenic nerve. Neurosurgery 17(6):974-984.

Whiteneck GG, Carter RE, Charlifue SW, et al. 1985 A Collaborative Study of High Quadriplegia. Grant Report, U.S. Department of Education, Rehabilitation Research and Demonstrations-Field Initiated Research. Contact: Gayle Whiteneck, Ph.D. (Craig Hospital, Englewood, Colorado). 